of examining the map now in Stockholm, he is convinced that it is simply a Dutch sea chart from the beginning of the seven teenth century, and of no value whatever, which he bolieves Baron Nordenskjöld did not, under a mere cursory examination, discover. In consequence of the opinion pronounced by our correspondent, the Swedish Geographical Society has decided not to have facsimiles of the map taken.

\section{INDIAN METEOROLOGY}

IJ.

THE title of Paper IV. - "Storms in Bengal, accompanied by increased Atmospheric Pressure and the Apparent Reversal of the Normal Diurnal Oscillation of the Barometer," by Prof. J. Eliot,-must necessarily appear somewhat strange to those accustomed in our latitudes to the frequent masking, if not actual reversal, of the normal diurnal os cillation, by the large and rapid non-periotic oscillations to which the atmospheric pressure is subject.

There are two reasons why this reversal should be rare in the tropics, and of such frequent occurrence, as to be more often the rule than the exception, in higher latitudes. One is, that the range of the diurnal barometric oscillation is greatest near the equator, and diminishes as we approach the poles, and the other, that the range of the non-periodic oscillations varies in preciscly the opposite way, increasing very nearly in the ratio (as Ferrel has shown) of the square of the sine of the latitude to unity. ${ }^{2}$

Instances of such inversion, are said by Prof. Eliot to be extremely rare in Bengal, but a perusal of the paper leads us to conclude that it is rather a case of de non apparentibus than de non existentibus, and that a tendency towards reversal take place to some extent in all north-westers and analogous storms of a sudden and violent character.

Humboldt, Col. Sykes, and Allan Brom, have all graphically described the regular march of the diurnal barometric oscillation, but their observations were mostly made a good deal nearer the equator than Bengal, and thus in regions where reversal of the diurnal oscillation would be a still rarer phenomenon.

In the cases cited by Eliot, including one observe 1 by Hill at Allahabad, the following characteristic changes were observed about the time of reversal :-

I. A marked rise of the barometer.

2. An equally marked and simultaneous fall of the thermometer.

3. A sudden decrease of the tension of aque sus vapour.

4. An instantaneous change of wind direction.

A consideration of all these features, leads the author to conclude that in these cases a downru'h of cold air belonging to an upper current (which is known to travel seawards in Bengal, and is theref rre dry) takes place in the centre of the area of low pressure belonging to the storm. On no other hypothesis, does it seem possible to explain all the facts, especially the rise in the barometer, and the fall in vapour tension.

A close study of these north-we ters, whether accompanied by reversals or not, and their analogues in other parts of the world, is certain to unravel much of the complexity surrounding such and all aërial disturbances, and as all facts bearing on them are valuable, and the present writer was for some time resident in a locality (Dacca) where they occur with marked intensity, he may perhaps be allowed to remark that one of the most peculiar features he has noticed in connection with them, is the almost instantaneous return of the wind to its original direction after the rear of the storm-clond has passed the zenith. Both before and after the storm, the wind in Bengal blows from the direction of the sea (south-east). The storm-cloud appears to form in the northwest by an aggregation of vapour that is carried thither in cloudlets from the sea. After a time, the threatening mass advances towards the sea, the sea-wind meanwhile blowing towards the advancing cloud with increased force, until the latter has arrived pretty close, when a lull takes place, after which the wind instantaneously changes to the opposite quarter (generally through the north), from which it blows with great violence. Then come the characteristics already noticed, togetber with continuous lightning and hail, the latter often very large.

When the storm-cloud, the rear of which presents a very

I Concluded from p. 407 .

2 "Relation between the Barometric Gradient and the Velocity of the Wind," by W. Ferrel. American Fom of Science, vol. viii., November, r 874 . definite outline, passe; the zenith, the wind invariably returns to its former direction, and gradually dies down as night approaches. The whole phenomenon appears to favour the notion which ha always been entertained by tiıe writer, and is merely a slight extension of the explanation given by Prof. Eliot, that a sudden oblique uprise of moist hot air takes place, deflecting the upper current into a corresponding oblique downward course, which determines the direction of the storm and continues as long as the uprising air interferes with its regular motion parallel to the surface. This explains why the storm always follows the course of the upper current, as well as the immediate readjustment of the original conditions, as soon as the region of ascending air which causes the deflection has passed the spot.

Paper V. "On the Rainfall of Benares in Relation to the Prevailing Winds," by S. A. Hill,-The observations utilised in this paper, as far as the velocity of the wind is concerned, raise a question of general importance, and one which we tbink ought to engage the attention of all thoughtful, and certainly all practical meteorologists. Up to I872, the anemometer was only I 5 feet above the ground, but in that year it was raised to a height of nearly 80 feet. Now what are we to think of the effect of such a change of position on the observations ?

According to Mr. Stevenson, 15 feet is the lowest elevation at which an anemometer should be placed, since below this height the velocity is found to be enormonsly affected by the nature of the surface. On the other hand, 80 feet is an elevation which would not only cause the instrument to register a considerably higher velocity, ${ }^{1}$ but also secure for it nearly complete immunity from the disturbing influences which would be sure to affect it in the lower position.

It is indeed very much to be regretted that in setting up anemometers in India no sort of uniformity seems to bave been attempted. Thus from a list of their elevations above the ground given in the "Meteorological Report for India" in 1876 , every variety of height imaginable occurs, ranging from 5 feet 7 inches at Khandwa to 76 feet II inches at Benares! At no two stations are the ancmometers at the same level, and though it is somewhat complacently admitted by Mr. Blanford "that it can hardly be affirmed that in the majority of cases the anemometric records are strictly comparable," one is naturally inclined to ask why the instruments could not bave been placed, if not exactly, at least more nearly, at the same level. Such an arrangement would seem to be a cardinal requisite where such a sensitive element as air motion is involved, and indeed Mr. Stevenson's experiments have shown that while observations below ${ }_{5}$ feet are almost useless, the velocity increases rapidly with the height through the first Ioo feet; so that until a correction is made for the height, it would be vain to attempt a comparison of observations made at lower, with those at higher levels.

Fortunately in this case the discussion mainly relates to the direction of the wind, so that the conclusions are not seriously affected by the change in the position of the instrument.

The chief conclusion arrived at by the author is similar to that obtained by $\mathrm{Mr}$. Blanford in the first paper of this series for Calcutta, except that Benares affurds no corroboration of the conclusion drawn from the former register, that "rain is the more probable in proportion as the deflection of the monsoon current is greater.

It appears, nevertheless, that there is a well-marked connection between the amount of rain that falls in $a$ day and the deflection of the rain-bearing current, the maximum amount being from the opposite quarter (north-west) to that from which the monsoon blows.

Paper VII. "Variations of Rainfall in Northern India," by S. A. Hill. - This is one of the most interesting and important papers of the whole series, its ostensible object being partly to test the soundness of the idea which was propounded by Dr. W. W. Hunter and others in 1877 , that sunspots, rainfall, and the occurrence of droughts and famines were closely associated in India. Regarding this vexata quastio it may be said at the ourset that while the general results of an investigation embracing an area which covers eleven degrees of latitude and twenty of longitude (equal to that of the British Isles, France, Germany, Austria, Holland, and Belgium combined), like those of Mr. Blanford for Southern India, bear out Meldrum's theory of an eleven-year cycle of rainfall, they exhibit certain irregularities, or, more properly speaking, double oscillations, which, as Prof.

I According to Mr. Stevenson's formula, which holds near the surface, the velocity would be increased by this change of position in the ratio $\mathrm{I}^{\circ} \mathrm{3}^{2}: \mathrm{I}$. Thus for 1872 the observed mean value was 678 . To make this com jarable with the years that follow, it should be $89^{\circ} 4$ ! 
Hill shows, are probably due to local reacting circumstances, and which afford but little hope of our ever being able to forecast droughts and famines in North-West India solely from a knowledge of the state of solar maculation.

The fact that the terrestrial effects of solar changes are conspicuous in some localities and almost totally absent in others seems to many persons incompatible with the cosmical nature of the influences at work, but to those who study the subject it appears, on the contrary, the only result to be reasonably expected both from experience and analogy.

Thus ordinary weather is the integral of all the differentiations effected during the regular seasonal changes in solar declination, and it need scarcely be remarked what an endless variety of conditions we have in this ease, due primarily to the operation of a gradual and periodic cause. Owing to diversities of superficial character, elevation, contour, latitude, \&c., we have reteorological oscillations set up, differing from each other in phase and amplitude, which, like the tides of the ocean, in some places tend to exaggerate and in others to annihilate each other. So also must it be, where we have solar changes which gradually perform their cycle in a period of years. The forced oscilla. tions they originate, though small, may in some localities, by a unison of oscillations of the same phase, or an absence of opposing oscillations, be exaggerated above the mean amplitude, just as in others they may, owing to an inequality of phase or the clashing together of opposite variations, be rendered inappreciable.

Prof. Eliot, in his " Report on the Meteorology of India for I877" (p. 3), evidently recognises this fact, when he admits the probability that "at one part of the sunspot period one effect of the variation of solar radiation may be to exaggerate local irregularity." While therefore it is probable that we shall find only a few places, where the terrestrial effects of solar spot variation are of sufficient magnitude and regularity to render secular forecasting possible (assuming that our foreknowledge of solar changes is reliable), such a fact ought by no means to be used as an argument against the utility of studying the relations between solar physics and terrestrial meteorology.

Mr. Blanford, who from the first attacked the somewhat crude hypothesis propounded by Dr. Hunter regarding sunspots and famines in Southern India, has in his own person furnished a practical protest against any such idea, since his researches on the connection between barometric pressure and sunspot variation have tended, not only to confirm the belief in the bond existing between solar and terrestrial changes, but have also opened out new collateral facls, which, if followed up, are certain to yield results of the highest importance to the science of meteorology. His own views on this question, which have frequently been misunderstood in certain quarters, and referred to as adverse to the general question, are concisely expressed in the following sentence, which we quote from an official report recently made by him to the Indian Government :-

"While, however, I am unable to concede to the conclusions hitherto placed on record, that degree of importance which has sometimes been claimed for them, as affording rules of guidance for the prognostication of scarcity and famine, I am fully in accord with the Famine Commis:ioners as to the importance of following up such clues as they afford, and of pursuing with all the means at our command the investigation of the class of phenomena to which they belong. It has happened again and again in the past history of science, that hypotheses, which in their original form were more or less erroneous, have nevertheless been most fruitful in their results. In giving system and definite purpose to research they have served a most useful office; and although the course of their verification may have resulted in demonstrating their error, the same process has brought to light the germs of new and unstspected truths which might have long remained hidden but for the stimulus to investigation afforded by rejected theories."

The nature of the entire question indeed, seems to have been a yood deal misunderstood in this country, at least to judge from the extraordinary amount of obloquy and opposition which it has encountered in various quarters.

On the one hand, it must be obvious to any one who casts even a merely superficial glance at the vast changes in the physical condition of the sun, indicated by the spots, prominences, \&c., and the dependence of all terrestrial meteorology on the quantity (and perhaps quality) of the heat radiated from our great luminary, that such changes in the former, must be reflected to some extent in the latter, as indeed they are universally allowed to be in the case of terrestrial magnetism. On the other hand, it is equally obvious to the merest tyro in meteorology, that such meteorological fluctuations, though in many cases distinctly recognis able, are not only of small average amplitude (especially in higi latitudes) when compared with those which occur, as we say at present, non-periodically, but take a period of years to accomplish their cycle. To imagine therefore, that such changes, even if thoroughly determined, will alone enable us to forecast the general weather of a season or a year, is manifestly irrational as far as these latitudes are concerned, while even in India and the tropics generally, we have grounds for believing that there are only a few places, where the extreme range of the oscillation bears a ratio to the non-periodic changes large enough to constitute it the dominant factor of the weather.

That when the conditions which regulate the larger and more irregular changes are better understood, a knowledge of the underlying secular meteorological changes coincident (or nearly so) with the varying phases of solar activity, will be of great assis. tance in framing seasonal forecasts, it is impossible to doubt. $\Delta$ the same time it seems strangely to have been overlooked by the majority of those who have interested themselves in this fascinating question, that though the sunspot variation in meteorological elements may alone be insufficient to form the basis of a practical system of weather prophecy, it is very likely to prove the key by which the entire weather problem may be solved, since, when once we know the precise qualitative as well as quantitative meteorological effects of a gradual secular change in the solar radiation, coincident with the sunspot cycle, we shall gain an immense insight into the way in which the larger and more rapid oscillations are effected by the ordinary changes in solar radiation, brought about by season, latitude, geographical locality, \&c., these latter ascillations only differing from the former, in being more frequent and of greater amplitude.

Prof. Hill in his investigation, adopts a plan which is obviously necessary to any one who knows the peculiarities of Indian meteorology, viz. the separate treatment of the summer and winter rainfalls.

The former season embraces the period from May to October, and the latter the remaining months. An eleven-year pericd, in favour of which there is a good deal of preliminary evidence, is assumed, in order to see if there is any correspondence with the analogous mean period of solar spot variation. The oscillation of the summer rainfall for the whole area about its mean, is then estimated for the cycle, and is found to accord generally with the results for Southern India, and with Meldrum's supposed universal law, in showing a direct variation with the sunspots, the range being twice as great as in Southern India. At the same time considerable irregularity is visible, some of the stations at the border of the monsonn region giving results contrary to the average variation. The winter rainfall on the other hand shows a much closer relation to the sunspots, the remarkable thing about it being, that instead of varying dircctiy, as the summer fall, it varies inversely with the spotted area.

The variation of this winter fall shown in the text is very regular, and confirms a conjecture hazarded by the present writer in 1877 , that the similar variation which he had previously shown to exist in the winter rainfall of Calcutta would be found to be more decidedly marked in the sub-Himalayan zone to the north of it (NATLRE, vol. xvi, p. 267, Meteorological Notes).

In a postscript to the paper Prof. Hill has worked out th variation from a longer series of observations, which were dis. covered, apparently by accident, at the Board of Revenue in Allahabad, and which, by means of registers kept in the Himalayan province of Kumanon, "to which the civil disturbances following the mutiny of I 857 did not extend," allows the cycle to be worked out for the period 1844 to 1878 . The final result given in the form of percentage variations from the mean, is as follows:-

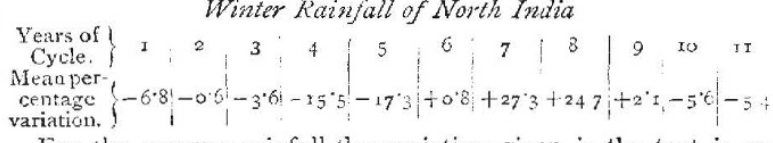

For the summer rainfall the variation given in the text is as follows :-

\section{Summer Rainfall of North India}

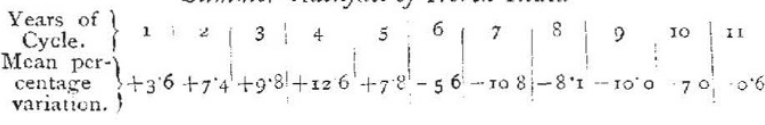


In the cycle as arranged above, the first year is that which cuntains the year of maximum sunspot, and the eighth that of minimum sunspot.

With the figures in the text, the maximu'n winter rainfall occurs on an average rather more than a year before the minimum of sunspots, and the mininum of rainfall appears either to coincides with, or to follow the maximum of the sunspots, at about an equal interval.

While, therefore, the facts are so far favourable to a close connection between sunspots and rainfall in Upper India, they do not lead so much to the conclusion that the former directly affect the latter, as to their both being effects of some common and as yet undetermined cause.

It should be further noticed, both as a result of this investigation, and an example of one of the "new and unsuspecter truths" which Mr. Blanford says are often incidentally brought to light, that the variations of the summer and winter falls are almost exactly contrary to each other, and as this has been found to occur not only in the years of the mean cycle, but also in individual years, it has been concluded by Prof. Hill that in Northern India the winter rains are excessive when the summer rains are defective and vice versa.

This contrary variation, which is of itself a valuable discovery, $i$ is moreover shown to be due in some measure to a reaction of the winter on the summer rainfall. Thus, in years of heavy winter rainfall in Northern India, and therefore of heavy snowfall in the Himalayas, an excess of barometric pressure attended by diminished temperature, is found to occur during the earlier months of the year, which causes the air to move ontwards from the centre of relatively highest pressure, and so bar the approach of the Arabian Sea current from the south-west, as well as the Bay of Bengal current from the south-east, and by thus compelling them to part with their moisture in other districts, such as the hills of Central India, or East Bengal and Burmah respectively, causes deficiency and drought over the Funjab and NorthWest Provinces, or Western Bengal.

On the other hand, in year: of defective winter rainfall, the temperature is generally high, and the pressure low, in the early months of the year; while the currents from the south-east up the Ganges valley appear in full strength, and are accompanied by early and abundant summer rains. ${ }^{1}$

Mr. Blanford has partly attributed the high atmospheric pressure which occurs in the years of heavy snowfall, to the cooling thereby produced, but as this abnormally high pressure sometimes extends right down the Bombay coast, it is plain that the snowfall is not the only determining cause, and that we must look to some more general cause to explain the matter. Prof. Hill speculates very intelligent'y on this cause, but as the speculation requires confirmatory evidence, it will be as well perhaps not to dwell on it at present.

It may, however, be observed that this speculation accounts satisfactorily for the double oscillation of the Bengal summer rainfall with its maxima at both sunspot epochs, as well as the double oscillation of the aunual rainfall of Southern India, noticed by the late Mr. J. A. Broun, F.R.S., in NATURE, vol. xvi. p. 334 (which, unlike that of Northern India, is solely due to the summer monsoon current) with its minima at both epochs, two remarkable facts, which might at first sight appear to be almost irreconcilable, if not unaccountable.

Before leaving this interesting and suggestive paper, it should be remarked that the variation in the winter rainfall of Northern India is shown to be closely connected with the curys of airtemperature in the tropics calculated up to I 862 by Dr. Köppen, and continued up to 1877 by Prof. Hill from Indian observations alone.

The following table gives the epochs of maxima and minima of both elements, and the conclusion can, we think, scarcely be resisted that there is a causal connection between them, since in every case but one, the rainfall epochs slightly follow those of the temperature :-

Maximum and Minimum Epochs of Tropical Temperature and

\begin{tabular}{|c|c|c|c|c|c|c|}
\hline \multicolumn{7}{|c|}{ Wuter Kain } \\
\hline Temperature. & & Rain. & & Temperatur & & Rain. \\
\hline 1836.9. & & $1837 \cdot 8$ & $\cdots$ & 18427 & & $1842 \cdot 7$ \\
\hline $1847 \cdot 7$ & $\ldots$ & $1848 \cdot I$ & ... & 18547 & ... & $1855^{\circ} \mathrm{O}$ \\
\hline $1858 \cdot 4$ & $\ldots$ & $1860^{\circ} 6$ & $\ldots$ & $1865^{\circ} \mathrm{I}$ & ... & 1865.5 \\
\hline $1874^{\circ} 8$ & $\ldots$ & I 8747 & $\ldots$ & $\left(1876^{\circ} 3\right)$ & $\ldots$ & $1876^{\circ} 0$ \\
\hline
\end{tabular}

I These opposite conditions are now so universally recogniced, as almost to for $m$ a canon of Indian metecrology.
Similar variations are shown to exist in the winter rainfall of other parts of the world, as well as in the humidity of Russia and Siberia, which favour the hypothesis long entertained both by Prof. Hill and the writer, that "the winter rains in Northern India occur simultanenusly with an increase in the quantity of aqueous vapour in the atmosphere over Eastern Furope and Western Asia, and that the cause of both may possibly be found in an unusually high temperature in the tropies, whereby the evaporation of the waters of the ocean is accelerated and the upper current of moist air known as the anti-trade has its velocity increased."

\section{SCIENTIFIC SERIALS}

Anterican foumal of Science, August.--Principal characters of American Jurassic Dinosaurs, part vi. : Restoration of Brontosaurus, with plate, by Prof. $O$. C. Marsh. The restoration is effected by bones belonging almost cxclusively to a single indi. vidual, which when alive was about fifty feet long; chief characteristics: long flexible neck, very short body, masive legs and feet, the latter plantigrade, and leaving fostprints about a square yard in extent, very large tail with solid bones, remarkably small head, smaller in proportion to the body than that of any other known vertebrate, skull being less in diameter or weight than the fourth or fifth cervical vertebra. The living animal must have weighed over twenty tons, and appears to have been a stupid reptile of slow motion, without offensive weapons or dermal armature, amphibious in habits, feeding on aquatic and other succulent plants. - The evolution of the American trotting horse, by Francis E. Nipher. The minimum time of trotting a mile, in a previous paper determined at 93 , is here reduced $t$ ? 91 second , and it is suggested that the trotter will very probably finally surpass the race-horse in speed.-On concave gratings: for optical purposes, by Henry A. Rowland, Professor of Physics, Johns Hopkins University, Baltimore.-Glacial markings of unusual forms in the Jaurentian Hills, by Dr. Edmund Andrews. Several illustrations are given of the peculiar marks here described, which are chiefly curver stria, serrated strix, and curious sconp-marks, both striated and unstriated, very difficult to explain on any theory of glacial action. - Response to the remarks of Messrs. Wachsmuth and Springer on the genera Glyptocrinu; and Reteocrinus, by S. A. Miller.-On the present status of the eccentricity theory of glacial climate, by W. J. McGee. In reply to recent critic the author urges scveral arguments in defence of Croll's theory of secular variations in terrestrial climate.--On the commingling of ancient faunal and modern floral types in the Laramie grour, by Charles A. White.-Notes on some fossil plants from Northern China, by J. S. Newberry. From the general character of the-e plants, which were collected by Mr. Arnold Hague, the anthor considers that Pumpelly and Richthofen's estimates of the great area and value of the North China coal and iron deposits are by no means unwarranted. The plants, all of the Carboniferou. age, seem to prove that the Chinese coal basins belong to tuo great geological systems, one answering to that of the European and American coal-measures, the other probably referable to the Rhœtic and L.ias.--Review of De Candolle's " Origin of Cultivated Plants," with annotations on certain American specie:, by Asa Gray and J. Hammond Trumbull.-On the supposed human footprints recently found in Nevada, by O. C. Marsh.

THE Journal of the Franklin Institute, August.-Cranes; a study of types and details, by Henry R. Towne.-A remarkable error in the common theory of the turbine water-wheel, by $\mathrm{J}$. P. Frizell.-Béton in combination with iron as a building material, by W. E. Ward. - The grindstone, by J. E. Mitchell,-The Glover tower and the working of sulphuric acid chambers, by Moses A. Walsh.-On radiant matter spectroseopy, a new method of spectrum analysis, by William Crookes, F. R.S.The cause of evident magnetism in iron, steel, and other magnetic metals, by D. E. Hughes, F.R.S.-National Exhibition of Railway Appliances, Chicago, Ill.-Obituary, Benjamin Howard Rand, Franklin Institute. - Notes.-Induced currents in reciprocal movements. - Twinkling of stars during auroras.-Spanish copper tubes. - Photozincography.-Orange peel.-Constitution of the sun.-Colour of distilled water.-Deep-sea explorations. -Generation of inflammable gases in the diffusion of beets.Amber.

Fournal of the Russian Chemical and Physical Sociely, vol. xv. fasc. 5.-On the formation and properties of oxide of 